九州大学学術情報リポジトリ

Kyushu University Institutional Repository

\title{
Study on the fuel balance of a DT reactor
}

Nishikawa, Masabumi

Graduate School of Engineering Science, Kyushu University

Tanabe, Tetsuo

Graduate School of Engineering Science, Kyushu University

http://hdl. handle. net/2324/26067

出版情報: Fusion Engineering and Design. 85 (7/9)，pp.987-991，2010-12. Elsevier バージョン:

権利関係: (C) 2009 Elsevier B.V. 


\title{
Study on the Fuel Balance of a DT Reactor
}

\author{
Masabumi Nishikawa and Tetsuo Tanabe \\ Graduate School of Engineering Science, Kyushu University, \\ Hakozaki 6-10-1, Higashi-ku, Fukuoka 812-8581, Japan
}

\begin{abstract}
The tritium balance in a DT fusion reactor is discussed in this paper. It is pointed out in this discussion that tritium balance in a fusion reactor is largely influenced by such uncertainties as plasma vessel effect, module effect and recovery efficiency of bred tritium required to estimate the overall tritium recovery efficiency and such uncertainties as overall burning efficiency of tritium in the plasma vessel, tritium trapping ratio at the first wall, loss due to $\beta$-decay of tritium inventory and designated reactor base tritium breeding ratio required to decide $(\beta)_{\text {overall }}$ to decide tritium balance.
\end{abstract}

KEY WORDS: tritium balance, recovery efficiency, burning efficiency, trapping efficiency 


\section{Introduction}

Tritium consumed in the plasma vessel of a DT fusion reactor must be supplied from the breeding blanket system through the main fueling system to maintain the self-sustainable DT nuclear burning because no effective tritium resources from outside are expected. Conditions necessary to achieve DT fuel self-sufficiency were previously discussed by Abdou et al [1]. They stated that the uncertainties due to nuclear data and calculation methods were found to be significant. It is found recently that a remarkable amount of tritium is possibly consumed in the plasma vessel by trapping into the re-deposition layer of the plasma facing materials. Accordingly it can be said that the uncertainties required to clear for discussion of tritium balance in a DT fusion reactor are rather increasing after discussion by Abdou et al.

The overall recovery efficiency of tritium in the tritium breeding system obtained from the neutron usage for breeding and efficiency in bred tritium recovery operation $(\boldsymbol{\beta})_{\text {overall, Max }}$ is compared with the overall recovery efficiency required to keep tritium balance in a DT fusion reactor $(\boldsymbol{\beta})_{\text {overall }}$ in this paper. $(\boldsymbol{\beta})_{\text {overall, Max }}$ which consists of the plasma vessel effect, the module effect and the recovery efficiency of bred tritium must be larger than $(\boldsymbol{\beta})_{\text {overall }}$ which is decided from the tritium balance in a fusion reactor related with the overall burning efficiency of tritium in the plasma vessel, the tritium loss ratio at the first wall, the tritium loss from the main fueling system and the loss due to $\beta$-decay of tritium forming active inventory and the designated reactor base tritium breeding ratio.

\section{Theoretical consideration on tritium balance}

\subsection{Tritium recovery efficiency from a fusion neutron}

One neutron is produced at one incident of the DT burning in the core of the plasma vessel. Then, tritium is produced using neutrons injected into the breeding part of the blanket. In this study, the maximum tritium breeding ratio expected per injected fusion neutron into the infinite volume of a mixture of breeding materials and neutron multipliers which is called as the neutron base tritium breeding ratio, is expressed as $(\boldsymbol{T B R})_{0}$ in this study. The value of $(\boldsymbol{T B R})_{0}$ is considered to be maximized with the way of preparation of the tritium breeding material and the neutron multipliers in the module with no construction materials. Accordingly, it may be said that $(\boldsymbol{T B R})_{\mathbf{0}}$ has a meaning resembling to the neutron multiplication factor in a fission reactor having an infinite volume.

Some portions of neutron formed at DT reactions are not used for tritium generation corresponding to the design of plasma vessel and that of blanket module. A certain portion of the first wall is not covered with blanket. Then, a certain portion of neutrons generated in the burning 
core cannot give any contribution to tritium breeding. This efficiency in neutron usage on tritium breeding due to limitation in the coverage of blanket is corrected by using the effective coverage of the first wall for breeding $\left(\boldsymbol{\beta}_{\mathbf{V V}}\right)_{\mathbf{B C}}$ in this study. Furthermore, some neutrons are consumed by interaction with the first wall materials or the armor materials and this effect is expressed as $\left(\boldsymbol{\beta}_{\mathbf{V v}}\right)_{\mathbf{F W}}$. Then, number of neutrons effectively injected to the blanket module is corrected by $\boldsymbol{\beta}_{\mathbf{V v}}$ named as the plasma vessel effect in usage of fusion neutron in this study.

$\boldsymbol{\beta}_{\mathrm{VV}}=\left(\boldsymbol{\beta}_{\mathrm{VV}}\right)_{\mathrm{BC}}\left(\boldsymbol{\beta}_{\mathrm{VV}}\right)_{\mathrm{FW}}$

Some portion of tritium injected into the blanket module disappears without contribution to tritium breeding because of interaction with construction materials forming the shell structure of the blanket module. This effect is corrected using the shell effect in the blanket module denoted by $\left(\boldsymbol{\beta}_{\text {MD }}\right)_{\text {SHELL }}$ in this study. Consumption of neutron with interaction of structural materials or piping materials in the blanket module is corrected by the structure effect $\left(\boldsymbol{\beta}_{\mathbf{M D}}\right)_{\text {STR }}$. Both effects related to the module structure give the module effect denoted by $\boldsymbol{\beta}_{\mathbf{M D}}$ in this study.

$\boldsymbol{\beta}_{\mathrm{MD}}=\left(\boldsymbol{\beta}_{\mathrm{MD}}\right)_{\text {SHELL }}\left(\boldsymbol{\beta}_{\mathrm{MD}}\right)_{\text {STR }}$

Then, the amount of tritium formed in the blanket system is expressed by

$\left(Q_{\mathrm{T}}\right)_{\mathrm{BRED}}=\boldsymbol{\beta}_{\mathrm{VV}} \boldsymbol{\beta}_{\mathrm{MD}}(T B R)_{0}($ Tburn $) \quad[\mathrm{g} / \mathrm{day}]$.

Some tritium generated in the blanket module may go out to the outer surroundings by permeation through construction materials or piping materials of the blanket system and this effect is corrected by the recovery efficiency of bred tritium denoted by $\boldsymbol{\beta}_{\mathbf{B T}}$. This factor consists of efficiency in the breeding part $\left(\boldsymbol{\beta}_{\mathbf{B T}}\right)_{\mathbf{B P}}$, efficiency in the piping part $\left(\boldsymbol{\beta}_{\mathbf{B T}}\right)_{\mathbf{P P}}$ and efficiency in the recovery part $\left(\boldsymbol{\beta}_{\mathrm{BT}}\right)_{\mathrm{RP}}$.

$\boldsymbol{\beta}_{\mathrm{BT}}=\left(\boldsymbol{\beta}_{\mathrm{BT}}\right)_{\mathrm{BP}}\left(\boldsymbol{\beta}_{\mathrm{BT}}\right)_{\mathrm{PP}}\left(\boldsymbol{\beta}_{\mathrm{BT}}\right)_{\mathrm{RP}}$

These correction factors are schematically shown in Fig. 1 for a solid blanket system. The similar schematic diagram is also made for a liquid blanket system. It is anticipated that the permeation loss of bred tritium to the coolant in the breeding part may decrease the recovery efficiency $\left(\boldsymbol{\beta}_{\mathbf{B T}}\right)_{\mathbf{B P}}$. It is also anticipated that permeation loss from the piping wall which connect the breeding part and the recovery part of the bred tritium is significant because the temperature of the purge gas from the blanket part is considered to be high. It is considered that this effect is possibly larger in the liquid blanket system. Then, development of certain methods to suppress permeation loss is required in case of need.After all, the amount of tritium obtained from the blanket system $\left(Q_{\mathrm{T}}\right)_{\mathrm{BS}}$ is shown as follows: $\left(Q_{\mathrm{T}}\right)_{\mathrm{BS}}=($ Tburn $)(\boldsymbol{T B R})_{0}(\boldsymbol{\beta})_{\text {overall, Max }} \quad[\mathrm{gT} / \mathrm{day}]$, $=($ Tburn $)(T B R)_{0} \beta_{\mathrm{VV}} \beta_{\mathrm{MD}} \beta_{\mathrm{BT}}$.

Here, $(\boldsymbol{\beta})_{\text {overall, Max }}$ shows the overall recovery efficiency in the tritium breeding system obtained from the neutron usage and efficiency in bred tritium recovery.

It is also expected in the blanket to obtain the larger value for the nuclear energy multiplication from the viewpoint of efficiency in the energy recovery. It is considered that use of the nuclear 
heating generated at the $(\mathrm{n}, \gamma)$ reaction with the construction material is considered to be more effective to obtain the energy than use of the heating at the ${ }^{6} \mathrm{Li}(\mathrm{n}, \alpha)$ reaction [2]. This means that the way to get larger tritium breeding ratio and the way to get larger energy multiplication compete each other. It is recommended in this discussion to give priority to the tritium breeding because to keep enough margin in the tritium breeding can be more difficult.

\subsection{Limitation on tritium recovery efficiency from tritium balance in a fusion reactor}

The tritium balance in a DT fusion reactor considered in this study is schematically summarized in Figure 2. The more details are reported elsewhere by the present author [3].

The implantation of energetic particles into the plasma facing components, surface adsorption, absorption into bulk of the first wall materials and co-deposition of tritium with material eroded from the plasma facing materials in deposition-dominated areas contribute to the overall tritium inventory in the plasma vessel [4]. It is considered that the tritium inventory from the first two mechanisms will rapidly reach saturation and that co-deposition will become the main source of the tritium accumulation in the plasma vessel. The third mechanism may proceed somehow slower than the first two mechanisms though the absorption rate and the absorption amount depend on material and operation temperature.

Tritium trapped to the first wall materials can be recovered at end of the service lifetime of the reactor or at the regular checkup with certain efficiency. Then, tritium recovered from the first wall of the plasma vessel is used as a part of tritium supplied to the next operation as shown by the dotted arrow in Fig.2. The frequency of the recovery operation of tritium from the first wall and the efficiency in tritium recovery gives profound effect not only on tritium economy but also on energy economy of a DT fusion reactor. Accordingly, development of the effective and economical technology to recover tritium from the co-deposition layer is important to keep the tritium economy of a DT fusion reactor.

Effect of the recovery operation on tritium economy will be discussed elsewhere.

Then, further discussion in this paper is performed without consideration on recovery from the co-deposition layer or the first wall. In other words, discussion in this paper is concentrated on the tritium balance of a DT commercial reactor in the first operational season before recovery operation.

The gain of the tritium from a DT fusion reactor is obtained by reduction of tritium burnt in plasma core and tritium loss in the reactor from the tritium bred in the breeding blanket as follows:

$$
\begin{aligned}
\left(Q_{\mathrm{T}}\right)_{\text {gain }} & =\left(Q_{\mathrm{T}}\right)_{\mathrm{BS}}-(\text { Tburn })-(\text { Tloss })_{\mathrm{VVtrap}}-(\text { Tloss })_{\mathrm{VVP}}-(\text { Tloss })_{\mathrm{FS}}-(\text { Tloss })_{\text {Decay }} \\
& =(\text { Tburn })\left[(\text { TBR })_{0}(\beta)_{\text {overall }}-\left\{1+\left(\delta_{\mathrm{T}}\right)_{\text {overall }} /(\eta)_{\text {overall }}+\left(\theta_{\mathrm{P}}\right)_{\text {overall }} /(\eta)_{\text {overall }}\right\}-\mu_{\mathrm{FS}} /(\eta)_{\text {overall }}\right. \\
& \left.-1.53 \times 10^{-4}(\text { Tinv })_{\text {total }} /(\text { Tburn })\right] \quad(\mathrm{gT} / \mathrm{day})
\end{aligned}
$$


Here, (Tburn) is the amount of tritium burnt per day in the burning core and evaluated from the designated power output and the efficiency in energy usage. The overall burning efficiency $(\boldsymbol{\eta})_{\text {overall }}$ used in this study including the efficiency in plasma formation in plasma vessel, the efficiency in plasma transfer to the burning core and the burning efficiency in the core.

(Tloss) $)_{\text {Vvtrap }}$ represents the trapping rate of tritium to the plasma facing materials and this retention rate is shown by the following equation consulting the recent reports on the plasma-wall interaction.

$(\text { Tloss })_{\mathrm{VVtrap}}=\left(\delta_{\mathrm{T}}\right)_{\text {overall }}\left(Q_{\mathrm{T}}\right)_{\mathrm{VVin}}, \quad(\mathrm{gT} / \mathrm{day})$.

where $\left(\boldsymbol{\delta}_{\mathrm{T}}\right)_{\text {overall }}$ is the overall trapping factor and $\left(\boldsymbol{Q}_{\mathrm{T}}\right)_{\mathrm{VVin}}$ is the introduction rate of tritium to the plasma vessel.

(Tloss) $)_{\mathrm{VvP}}$ represents the rate of tritium loss due to permeation through the first wall materials and the loss rate is shown by the following equation using overall permeation factor $\left(\boldsymbol{\theta}_{\mathbf{P}}\right)_{\text {overall }}$.

$(\text { Tloss })_{\mathrm{VVP}}=\left(\boldsymbol{\theta}_{\mathrm{P}}\right)_{\text {overall }}\left(\boldsymbol{Q}_{\mathrm{T}}\right)_{\mathrm{VVin}} \quad(\mathrm{gT} / \mathrm{day})$.

Then, the whole tritium loss at the first wall of the plasma vessel is given as follows in this study:

$(\text { Tloss })_{\mathrm{VV}}=\left\{\left(\delta_{\mathrm{T}}\right)_{\text {overall }}+\left(\boldsymbol{\theta}_{\mathrm{P}}\right)_{\text {overall }}\right\}\left(\boldsymbol{Q}_{\mathrm{T}}\right)_{\mathrm{VVin}} \quad(\mathrm{gT} /$ day $)$.

(Tloss) $_{\mathbf{F S}}$ is the rate of tritium loss in the main fueling system and is shown by the following equation using the overall tritium loss ratio $\boldsymbol{\mu}_{\mathrm{FS}}$ in this system.

$(\text { Tloss })_{\mathrm{FS}}=\mu_{\mathrm{FS}}\left(Q_{\mathrm{T}}\right)_{\mathrm{FS}}=\mu_{\mathrm{FS}}\left(Q_{\mathrm{T}}\right)_{\mathrm{VVin}} \quad(\mathrm{gT} /$ day $)$.

(Tloss) $)_{\text {Decay }}$ is the rate of tritium loss due to $\beta$-decay of tritium forming the active inventory and is shown by

$$
\begin{aligned}
(\text { Tloss })_{\text {Decay }} & =1.53 \times 10^{-4}(\text { Tinv })_{\text {total }} \quad(\mathrm{gT} / \text { day }), \\
& =1.53 \times 10^{-4}\left(\boldsymbol{n}_{\text {stock }}\right)(\text { Tburn }), \quad(\mathrm{gT} / \mathrm{day}),
\end{aligned}
$$

where (Tinv) $)_{\text {total }}$ represents the sum of the dynamic inventory of active tritium in the fusion reactor and the static inventory kept in the storage. In the estimation of this study, the total inventory is expressed by the amount of tritium required for burning for $\boldsymbol{n}_{\text {stock }}$ days in the burning core as shown by Eq. (12).

Then, the overall tritium breeding ratio in a fusion reactor $(\boldsymbol{T B R})_{\mathbf{R}}$, reactor base tritium breeding ratio, is defined as follows:

$$
\begin{aligned}
(T B R)_{\mathbf{R}} & =\left\{\left(Q_{\mathrm{T}}\right)_{\text {gain }}+(\text { Tburn })\right\} /(\text { Tburn }) \\
& =(T B R)_{0}(\beta)_{\text {overall }}-\left\{\left(\delta_{\mathrm{T}}\right)_{\text {overall }}+\left(\boldsymbol{\theta}_{\mathrm{P}}\right)_{\text {overall }}+\mu_{\mathrm{FS}}\right\} /(\eta)_{\text {overall }}-1.53 \times 10^{-4}\left(\boldsymbol{n}_{\text {stock }}\right) \\
& =(\boldsymbol{T B R})_{0}(\boldsymbol{\beta})_{\text {overall }}-\left(\Delta_{\mathrm{T}}\right)_{\text {overall }} /(\eta)_{\text {overall }}-1.53 \times 10^{-4}\left(\boldsymbol{n}_{\text {stock }}\right) .
\end{aligned}
$$

where $\left(\Delta_{T}\right)_{\text {overall }}$ is the total tritium loss ratio in the whole fueling cycle which consists of the plasma vessel and the main fueling system. It is considered that this factor generally represents the tritium loss in the plasma vessel because $\boldsymbol{\mu}_{\mathrm{FS}}$ under the steady operation is considered to be small from tritium handling experiences so far.

Because $(\boldsymbol{T B R})_{\mathbf{R}}$ shows the overall effectiveness of neutron usage in tritium breeding, it can be said that this factor corresponds to the effective multiplication factor of neutron in a fission reactor if it is 
considered that $(\boldsymbol{T B R})_{0}$ has the meaning of the multiplication factor.

The allowable limit of the overall recovery efficiency in the tritium breeding system obtained from the tritium balance in a reactor must satisfy the following condition to maintain the tritium balance in the reactor.

$1 \geqq(\beta)_{\text {overall }} \geqq\left\{(T B R)_{R}+\left(\Delta_{T}\right)_{\text {overall }} /(\eta)_{\text {overall }}+1.53 \times 10^{-4}\left(n_{\text {stock }}\right)\right\} /(T B R)_{0}$,

The value of $(\boldsymbol{\beta})_{\text {overall }}$ must not exceed the value of $(\boldsymbol{\beta})_{\text {overall, Max }}$ which is obtained from the neutron usage in the tritium breeding system and recovery efficiency of the bred tritium.

$(\boldsymbol{\beta})_{\text {overall, Max }} \geqq(\boldsymbol{\beta})_{\text {overall }}$

The tritium balancing factor in a DT fusion reactor defined by the following equation in this study must be larger than 1 to maintain the tritium balance in a fusion reactor.

$\Gamma_{\mathbf{T}}=\left\{(\boldsymbol{\beta})_{\text {overall }}(\boldsymbol{T B R})_{0}\right\} /\left\{(\boldsymbol{T B R})_{\mathbf{R}}+\left(\Delta_{\mathrm{T}}\right)_{\text {overall }} /(\boldsymbol{\eta})_{\text {overall }}+1.53 \times 10^{-4}\left(\boldsymbol{n}_{\text {stock }}\right)\right\}$.

\section{Results and discussion}

The tritium balancing factor is shown in Fig. 3 to check the effect of the overall recovery efficiency in the tritium breeding system on the tritium balance where $\left(\Delta_{T}\right)_{\text {overall }} /(\boldsymbol{\eta})_{\text {overall }}$ is used in the abscissa. The value of 1.6 is used as the standard of $(\boldsymbol{T B R})_{0}$ in this study because the neutronics estimation for the ${ }^{6} \mathrm{Li}_{2} \mathrm{TiO}_{3}$ - $\mathrm{Be}$ system can give this breeding ratio [4]. Estimation of the tritium breeding ratio per $14 \mathrm{MeV}$ neutron in lithium lead by Watanabe shows that the tritium breeding ratio of 1.61 is obtained when the thickness of lithium lead is more than $2 \mathrm{~m}$ [5]. In this discussion 45 days are taken for $\boldsymbol{n}_{\text {stock}}$, where $\boldsymbol{n}_{\text {stock }}$ consists of 30 days for storage, 12 days for active inventory in main fuel cycle and 3 days for inventory in blanket system in this study [6].

$\left(\boldsymbol{\Gamma}_{\mathrm{T}}\right)_{\mathrm{VV}}=\left(\Delta_{\mathrm{T}}\right)_{\text {overall }} /(\boldsymbol{\eta})_{\text {overall }}$.

This ratio is named as the tritium balancing factor in the plasma vessel by the present author considering that $\left(\Delta_{T}\right)_{\text {overall }}$ mainly represents the tritium loss at the first wall and $(\boldsymbol{\eta})_{\text {overall }}$ represents the neutron production (i.e. tritium production) in the plasma vessel. Fig. 3 shows that $\left(\boldsymbol{\Gamma}_{\mathbf{T}}\right)_{\mathbf{v v}}$ should be smaller than 0.173 when $(\boldsymbol{\beta})_{\text {overall }}$ is 0.8 though $\left(\boldsymbol{\Gamma}_{\mathbf{T}}\right)_{\mathbf{V V}}$ should be smaller than 0.0131 when 0.7 is obliged to use for $(\boldsymbol{\beta})_{\text {overall }}\left(\boldsymbol{\Gamma}_{\mathrm{T}}\right)_{\mathrm{VV}}$ of 0.173 corresponds to $(\boldsymbol{\eta})_{\text {overall }}$ of $0.17 \%$ and $\left(\boldsymbol{\Gamma}_{\mathrm{T}}\right)_{\mathrm{VV}}$ of 0.0131 corresponds to $(\boldsymbol{\eta})_{\text {overall }}$ of $2.3 \%$ if $\left(\Delta_{\mathrm{T}}\right)_{\text {overall }}$ is $3 / 10000$. This figure also shows that the tritium balance in a fusion reactor is not obtained at all when the expected value for $(\boldsymbol{\beta})_{\text {overall }}$ is a little smaller than 0.7 under the condition of estimation for this figure $\left((\boldsymbol{T B R})_{0}=1.6,(\boldsymbol{T B R})_{\mathrm{R}}=1.1\right.$ and $\boldsymbol{n}_{\text {stock }}=45$ days).

The effect of the tritium balancing factor in the plasma vessel on the required recovery efficiency is shown in Fig. 4 where $(\boldsymbol{T B R})_{\mathbf{R}}$ is used as the parameter. It is known from this figure that the required overall recovery efficiency in the tritium breeding system $(\boldsymbol{\beta})_{\text {overall }}$ is so large as 0.817 when $\left(\boldsymbol{\Gamma}_{\mathbf{T}}\right)_{\mathbf{V V}}$ is 0.2 and 0.723 when $\left(\boldsymbol{\Gamma}_{\mathbf{T}}\right)_{\mathbf{V V}}$ is 0.05 . It is anticipated by the present authors that $(\boldsymbol{\beta})_{\text {overall, Max }}$ 
is not larger than 0.8 after discussions with researchers on reactor design. It is also known from this figure that the tritium economy in a fusion reactor fails when $\left(\boldsymbol{\Gamma}_{\mathbf{T}}\right)_{\mathbf{V V}}$ is larger than 0.493 because recovery efficiency more than 1.0 is demanded to the breeding system.

The example value for the tritium balancing factor in the plasma vessel is compared in Table 1 assuming that the tritium trapping ratio reported by Roth et al [7].

Effect of the overall burning efficiency on the required recovery efficiency is compared in Fig. 5 for various first wall materials. This figure implies that only the all $\mathrm{W}$ first wall may afford the tritium balance when the overall burning efficiency of $1 \%$ is available in the plasma vessel and $(\boldsymbol{\beta}))_{\text {overall, Max }}$ larger than 0.723 is attained under the condition of this discussion. Use of Be wall with W diverter demands 0.88 for $(\boldsymbol{\beta}))_{\text {overall }}$ and this value is considered to be smaller than $\left.(\boldsymbol{\beta})\right)_{\text {overall, Max. }}$

When judging is made from Fig. 5, it is not recommended to use graphite materials for the first wall unless otherwise trapping ratio of tritium to graphite wall decreases by two orders under the commercial reactor conditions.

It is needless to say that the tritium balancing factor in the plasma vessel $\left(\boldsymbol{\Gamma}_{\mathbf{T}}\right)_{\mathbf{V V}}$ has the smaller value when the larger overall burning efficiency in the plasma vessel or the smaller overall trapping ratio is demonstrated by the ITER or its successors. Then, the allowable limit required for the overall recovery efficiency in the tritium breeding system becomes lower. As is shown in Figs. 4 and 5, the effect of change in the balancing factor in the plasma vessel on the required efficiency becomes much smaller when $\left(\boldsymbol{\Gamma}_{\mathbf{T}}\right)_{\mathbf{V V}}$ is smaller than 0.03 .

The effective area to give the affirmative value for the tritium balance in the $\left(\boldsymbol{\Gamma}_{\mathrm{T}}\right)_{\mathrm{Vv}}-(\boldsymbol{\beta})_{\text {overall }}$ chart is shown by Fig. 6 where $(\boldsymbol{T B R})_{\mathbf{R}}$ is used as the parameter. The lower limit of the effective area is decided by $(\boldsymbol{\beta})_{\text {overall }}$ which is obtained from the tritium balance in the fusion reactor and the upper limit is decided by $(\boldsymbol{\beta})_{\text {overall, Max }}$ which is obtained from the neutron balance in the tritium breeding system and recovery efficiency of the bred tritium. When the attainable tritium balancing factor in the plasma vessel is smaller, in other words larger overall efficiency in tritium burning or smaller overall tritium loss ratio at the first wall is attained, the allowable recovery efficiency in the tritium breeding system can become smaller.

\section{Conclusion}

From the view point of tritium research in the blanket system, it is important to secure the large enough value for $(\boldsymbol{\beta})_{\text {overall, Max }}$ to meet the required recovery efficiency $(\boldsymbol{\beta})_{\text {overall }}$ to maintain the tritium balance. When the largest attainable overall burning efficiency in the plasma vessel is denoted as $(\boldsymbol{\eta})_{\text {overall, Max }}$ and the smallest attainable overall tritium loss ratio at the first wall is denoted as $\left(\Delta_{\mathrm{T}}\right)_{\text {overall, Min }},\left(\boldsymbol{\Gamma}_{\mathrm{T}}\right)_{\mathrm{VV}, \operatorname{Min}}\left(=\left(\Delta_{\mathrm{T}}\right)_{\text {overall, Min }} /(\boldsymbol{\eta})_{\text {overall, Max }}\right)$ gives the lowest limit for $\left(\boldsymbol{\Gamma}_{\mathrm{T}}\right)_{\mathrm{VV}}$ as is shown in Fig. 5. Unfortunately, the quantification basis of $(\boldsymbol{\beta})_{\text {overall, Max, }}(\boldsymbol{\eta})_{\text {overall, Max }}$ or 
$(\Delta \mathbf{T})_{\text {overall, Min }}$ under the commercial fusion reactor condition is insufficient at present.

\section{Nomenclatures}

$(n)_{\text {stock }}$ : Equivalent burning days of tritium inventory (=(Tinv) $)_{\text {total }} /($ Tburn $\left.)\right)$, [day]

$\left(Q_{\mathrm{T}}\right)_{\text {gain }}$ : Gain of tritium from a DT fusion reactor, [gT/day]

$\left(\boldsymbol{Q}_{\mathrm{T}}\right)_{\mathrm{VVin}}$ : Flow rate of tritium to plasma vacuum vessel, [gT/day]

$\left(Q_{\mathrm{T}}\right)_{\mathrm{VVout}}$ : Flow rate of tritium from plasma vacuum vessel, [gT/day]

$\left(Q_{\mathrm{T}}\right)_{\text {BS: }}$ : Tritium obtained from blanket system, [g-T/day]

$\left(Q_{\mathrm{T}}\right)_{\mathrm{FS}}$ : Flow rate of tritium in fueling system, [g-T/day]

(Tinv): Inventory of active tritium [gT]

(Tburn): Tritium burning rate in plasma vacuum vessel, [gT/day]

(Tburn) $)_{0}$ : Tritium burning rate in plasma vacuum vessel when energy efficiency is 1 , [gT/day]

(Tburn) $)_{\mathrm{Y}}$ : Annual tritium burning rate in plasma vacuum vessel, [gT/year]

$(\boldsymbol{T B R})_{0}$ : Tritium breeding ratio for mixture of breeder and neutron multiplier, [-]

$(\boldsymbol{T B R})_{\mathrm{BS}}$ : Blanket base tritium breeding ratio for mixture of breeder and neutron multiplier, [-]

$(\boldsymbol{T B R})_{\mathbf{R}}$ : Reactor base tritium breeding ratio, [-]

(Tinv) $)_{\text {total }}$ : Active inventory of tritium in a DT reactor $[\mathrm{gT}]$

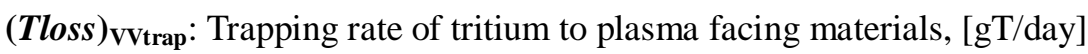

(Tloss) $_{\mathbf{V v P p}}$ : Tritium loss due to permeation through first wall, [gT/day]

(Tloss) $_{\mathrm{FS}}$ : Tritium loss in fueling system, [gT/day]

(Tloss) $)_{\text {Decay: }}$ Tritium loss due to $\beta$ decay in inventory of active tritium, [gT/day]

$(\boldsymbol{\beta})_{\text {overall }}$ : Overall recovery efficiency of tritium obtained from tritium balance, [-]

$(\boldsymbol{\beta})_{\text {overall, Max: }}$ Maximum attainable overall recovery efficiency of tritium obtained from neutron usage and recovery efficiency of bred tritium, [-]

$(\boldsymbol{\delta})$ : Trapping factor of tritium to co-deposition layer, [-]

$\left(\boldsymbol{\delta}_{\mathrm{T}}\right)_{\text {overall }}$ : Overall trapping factor of tritium to first wall, [-]

$\left(\Delta_{\mathrm{T}}\right)_{\text {overall }}$ : Overall tritium loss ratio in whole fueling cycle, [-]

$\left(\Delta_{T}\right)_{\text {overall, Min: }}$ Practically attainable minimum tritium loss ratio, [-]

$(\varepsilon)_{\text {overall: }}$ Overall efficiency in usage of fusion output for electricity, [-]

$\boldsymbol{\Gamma}_{\mathbf{T}}$ : Tritium balancing factor in a DT fusion reactor, [-]

$\left(\boldsymbol{\Gamma}_{\mathrm{T}}\right)_{\mathrm{VV}}$ : Tritium balancing factor in plasma vessel $\left(=\left(\boldsymbol{\Delta}_{\mathrm{T}}\right)_{\text {overall }} /(\boldsymbol{\eta})_{\text {overall }}\right),[-]$

$(\boldsymbol{\eta})_{\text {overall }}$ Overall burning efficiency of tritium in plasma vacuum vessel, [-]

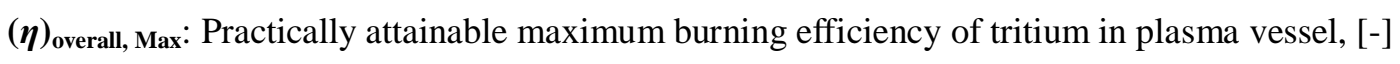

$(\boldsymbol{\theta})_{\text {overall: }}$ Overall permeation factor of tritium through first wall, [-] 
$(\boldsymbol{\mu})_{\mathrm{FS}}$ : Overall tritium loss ratio in fueling system, [-]

\section{References}

[1] M. A. Abdou, E. L. Vold, C. Y. Gung, M. Z. Youssef and K. Shin, "Deuterium-Tritium Fuel self-sufficiency in Fusion Reactors," Fusion Technology, 9, 250-285(1986).

[2] T. Matsui, H. Nakashima, M. Ohta, O. Motojima, M. Nakasuga, A. Iiyoshi and K. Uo, "Nuclear design of a Heliotron-H Fusion Power Reactor,” J. Fusion Energy, 4, 45-55 (1985).

[3] M. Nishikawa, "Study on tritium balance in a DT fusion reactor, Fusion Sci. and Tech., in printing. Partly reported at $11^{\text {th }}$ ITPA SOL/diverter meeting, Nagasaki Japan, Sept. 15-18, 2008.

[4] R.A. Causey, "Hydrogen isotope retention and recycling in fusion reactor plasma-facing components," J. Nucl. Mater., 300, 91- 117(2002).

[5] Y. YANAGI et al., "Nuclear and Thermal Analysis of Supercritical-water-cooled Solid Breeder Blanket for Fusion Demo Reactor," J. Nucl. Sci. Technol., 38, 1014-1018(2001).

[6] Y. Watanabe, Private communication about tritium breeding ratio in liquid breeders, 2006.

[7] M.NISHIKAWA et al., "Tritium inventory estimation in solid blanket system," Fusion Eng. and Des., 39-40, 615-625(1998).

[8] J. ROTH et al., "Recent analysis of key plasma wall interactions issues for ITER," J. Nucl. Maters. (2009), doi:10.1016/j.jnucmat.2009.01.037. 
Caption of figures

Fig. 1. Various factors having effect on recovery efficiency of tritium in the tritium breeding system.

Fig. 2. Tritium balance in a DT fusion reactor.

Fig. 3. Effect of $\left(\boldsymbol{\Gamma}_{\mathbf{T}}\right)_{\mathbf{V v}}$ on $\boldsymbol{\Gamma}_{\mathbf{T}}$ (parameter: $(\boldsymbol{\beta})_{\text {overall }}$ ).

Fig. 4. Effect of $\left(\boldsymbol{\Gamma}_{\mathbf{T}}\right)_{\mathbf{V V}}$ on required recovery efficiency in tritium breeding system.

Fig. 5. Effect of first wall material on required recovery efficiency in tritium breeding system.

Fig. 6. Effective area to give affirmative value for tritium balancing factor in $\left(\boldsymbol{\Gamma}_{\mathbf{T}}\right)_{\mathbf{V v}}-(\boldsymbol{\beta})_{\text {overall }}$ chart (parameter: $\left.(\boldsymbol{T B R})_{\mathbf{R}}\right)$. 


\section{Caption of table}

Table 1 Estimated value for tritium balancing factor in plasma vessel using tritium trapping ratio reported by Roth et al. 
- Plasma vessel effect $\beta_{\mathrm{VV}}=\left(\beta_{\mathrm{VV}}\right)_{\mathrm{BC}}\left(\beta_{\mathrm{VV}}\right)_{\mathrm{FW}}$

$\left(\boldsymbol{\beta}_{\mathbf{V V}}\right)_{\mathbf{B C}}$ : blanket coverage

$\left(\boldsymbol{\beta}_{\mathbf{V V}}\right)_{\mathbf{F W}}$ : neutron consumption

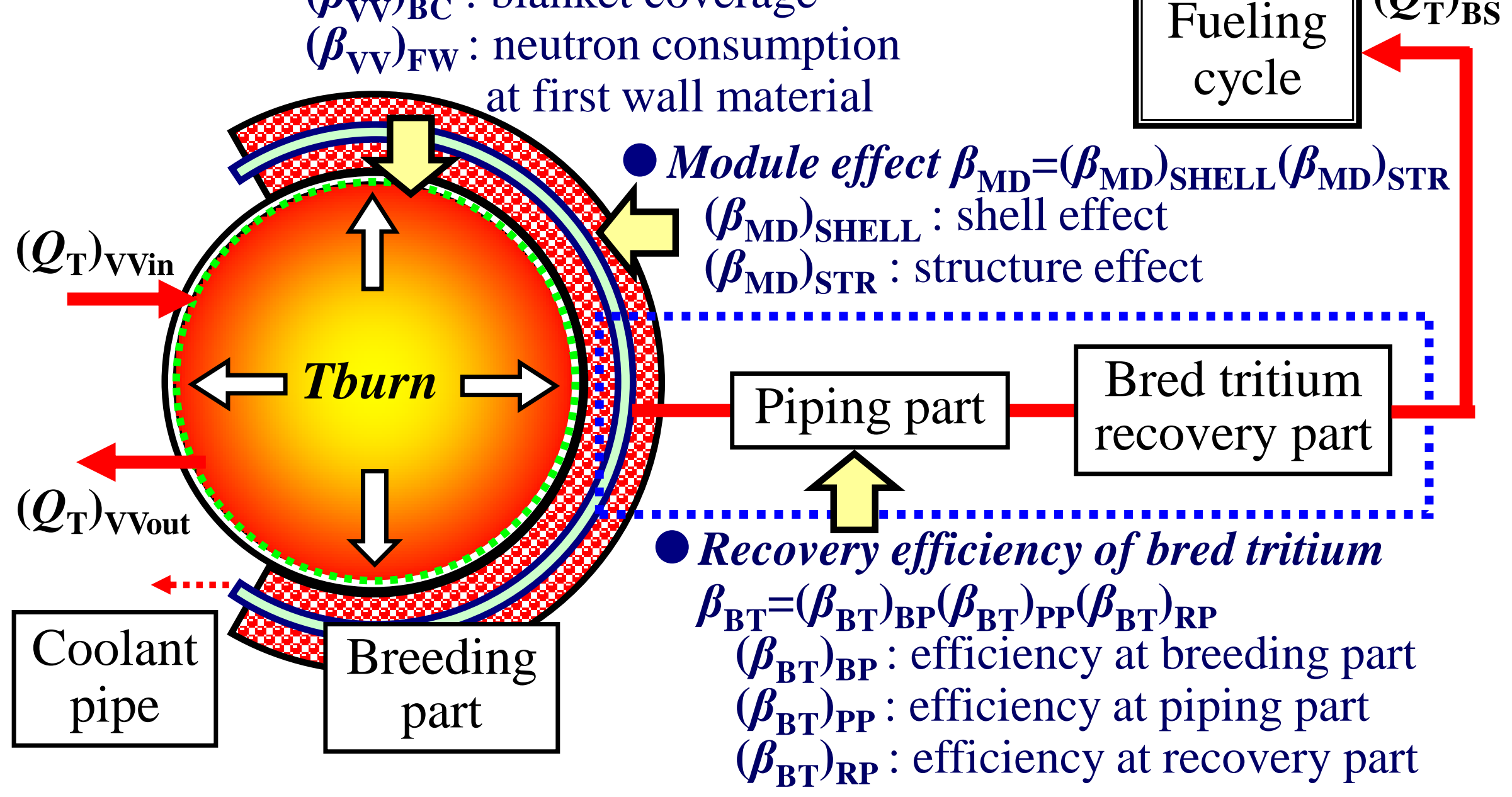

Maximum obtainable recovery efficiency $(\beta)_{\text {overall, Max }}=\beta_{\mathrm{VV}} \boldsymbol{\beta}_{\mathrm{MD}} \boldsymbol{\beta}_{\mathrm{BT}}$

Fig. 1. Various factors having effect on recovery efficiency of tritium in the tritium breeding system 


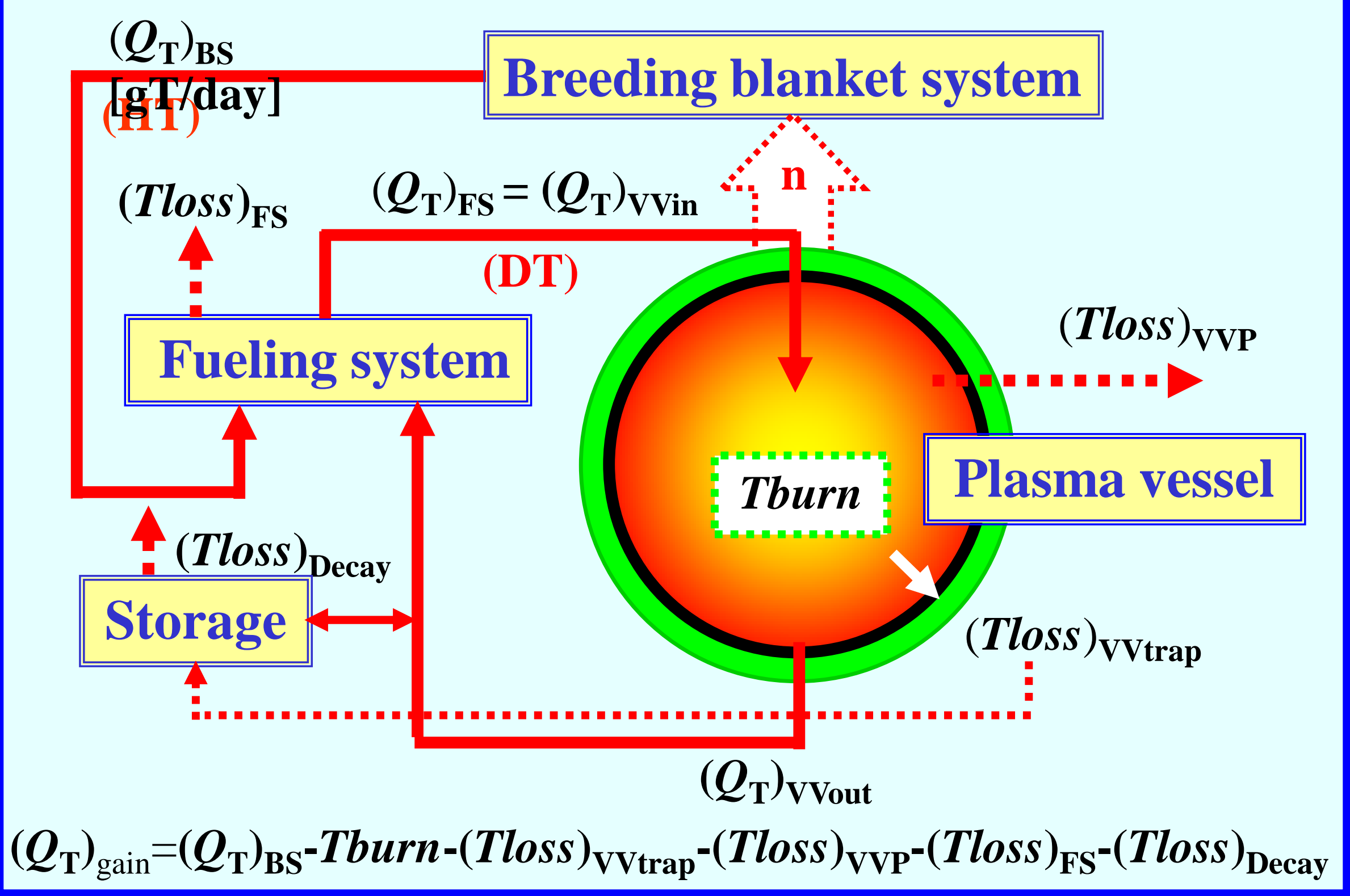

Fig. 2. Tritium balance in a DT fusion reactor. 


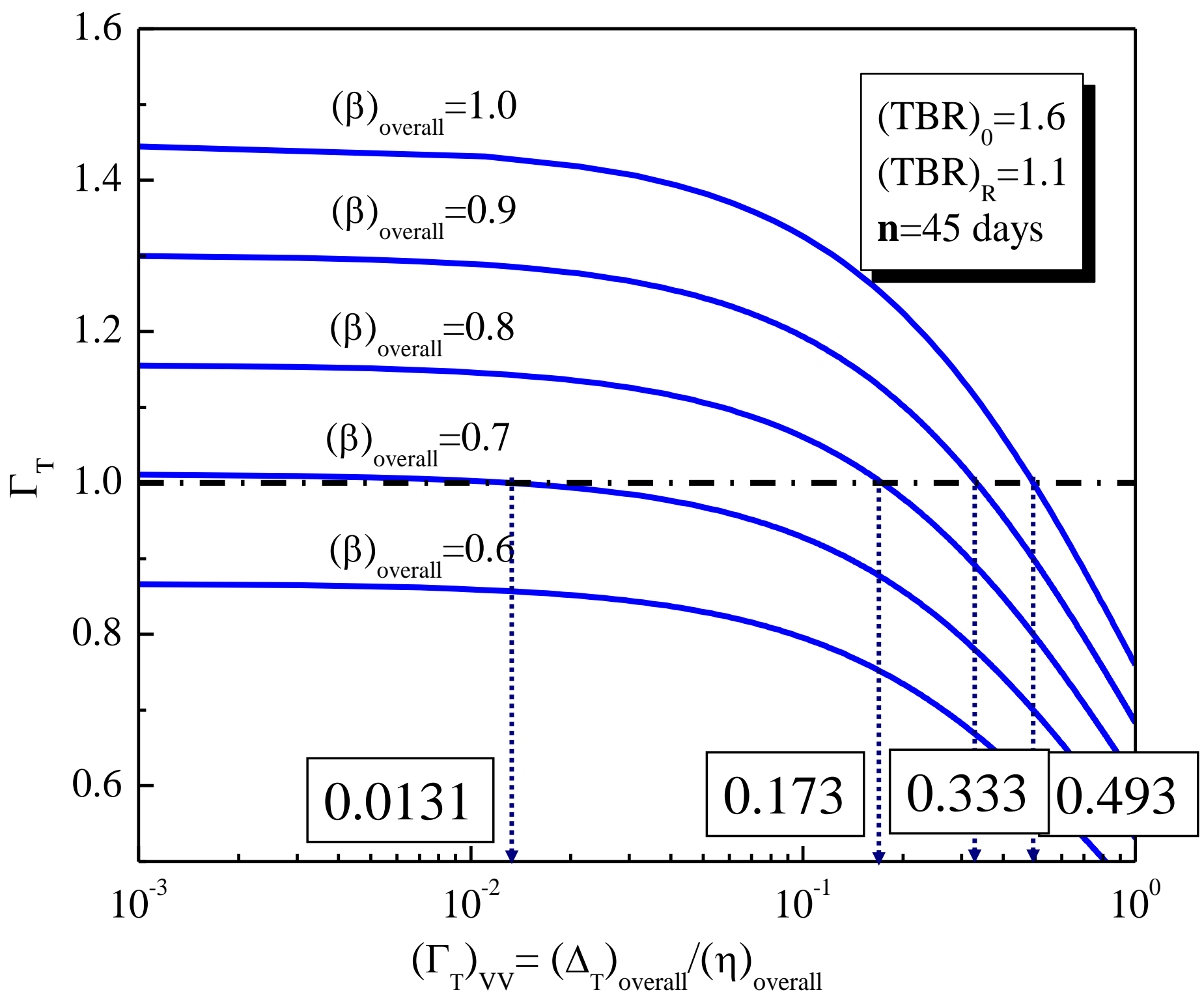

Fig. 3. Effect of $\left(\Gamma_{T}\right)_{V V}$ on $\Gamma_{T}$ (parameter: $\left.(\beta)_{\text {overall }}\right)$. 


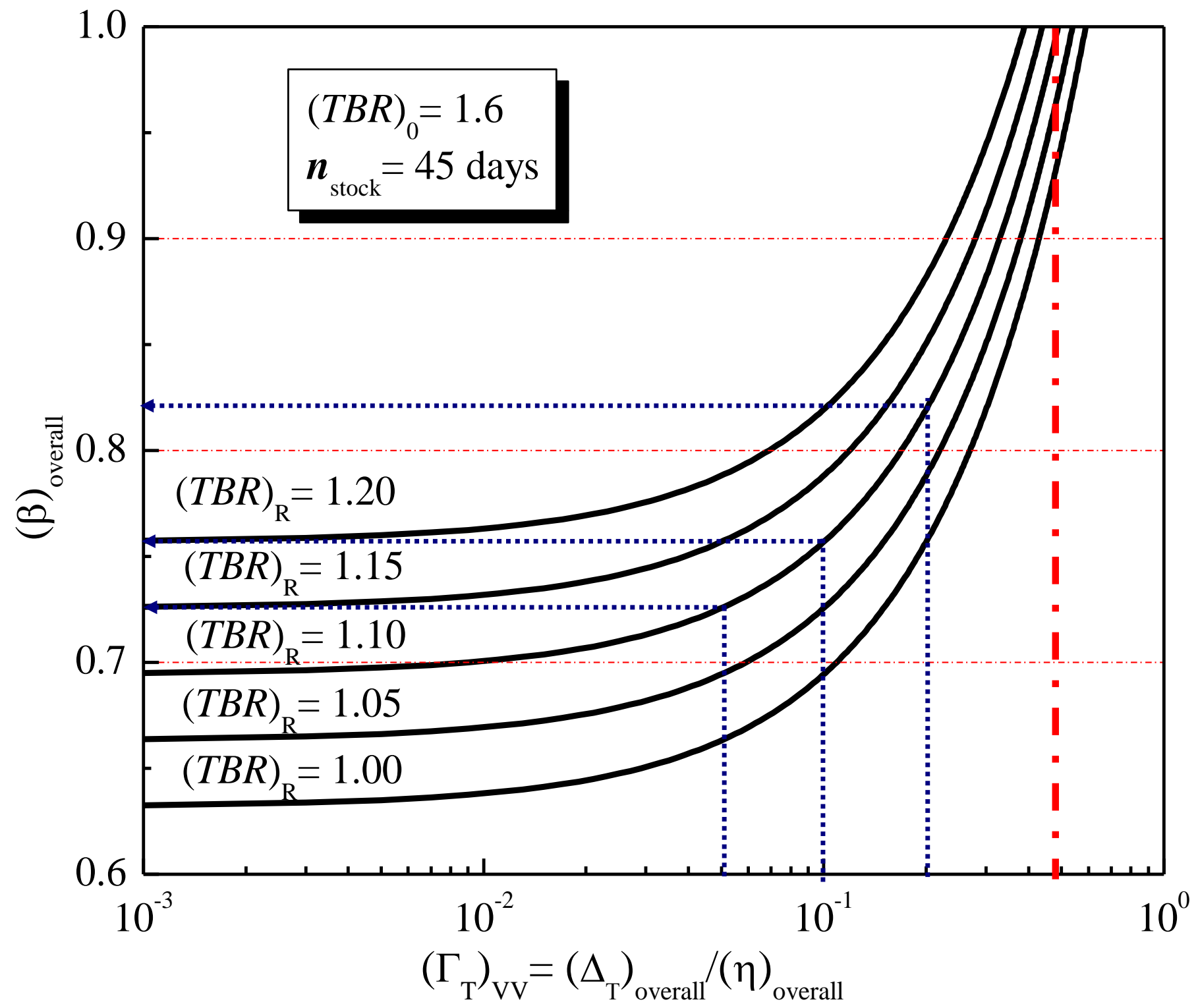

Fig. 4. Effect of $\left(\Gamma_{T}\right)_{\mathrm{VV}}$ on required recovery efficiency in tritium breeding system. 


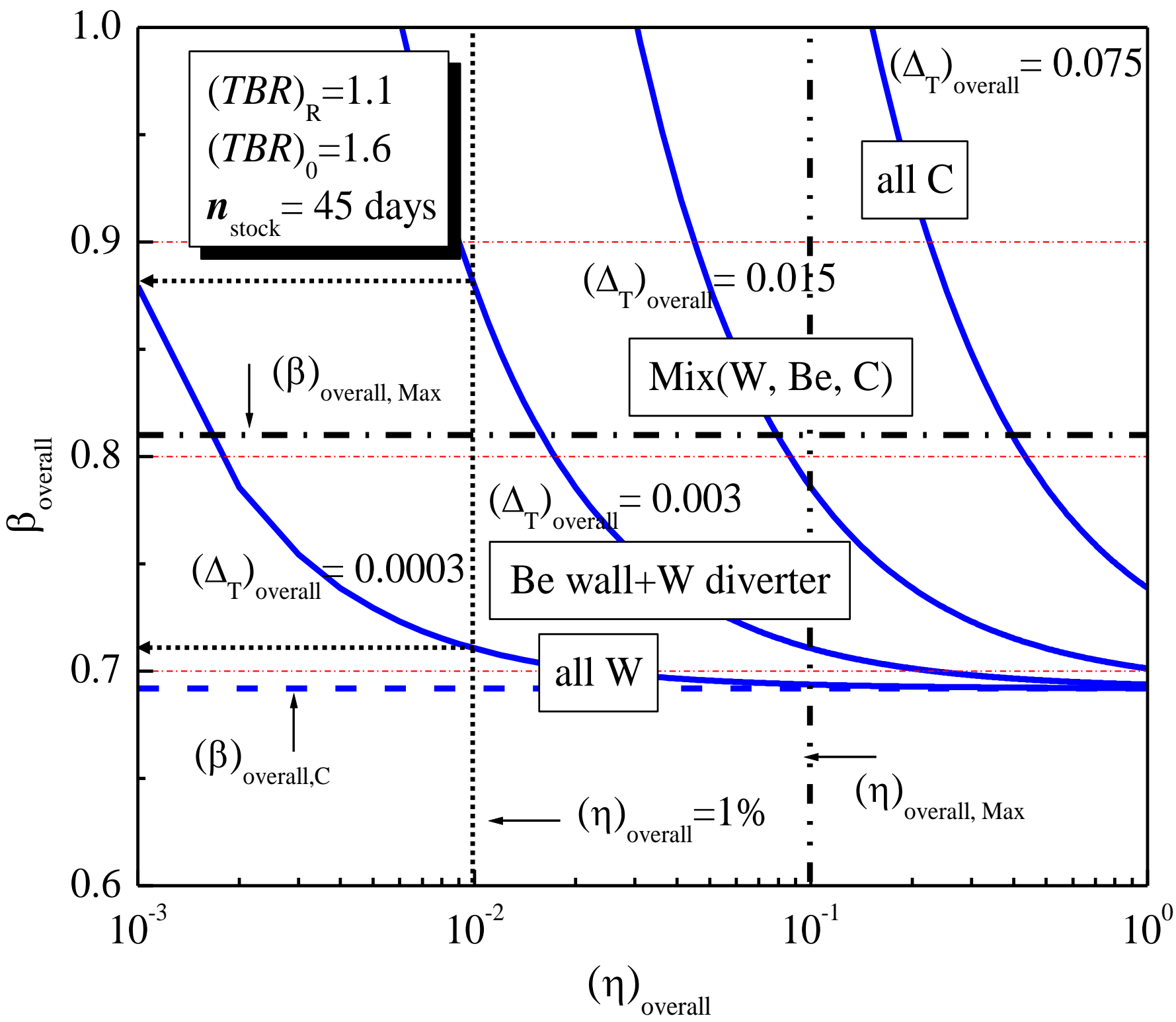

Fig. 5. Effect of first wall material on required recovery efficiency in tritium breeding system. 


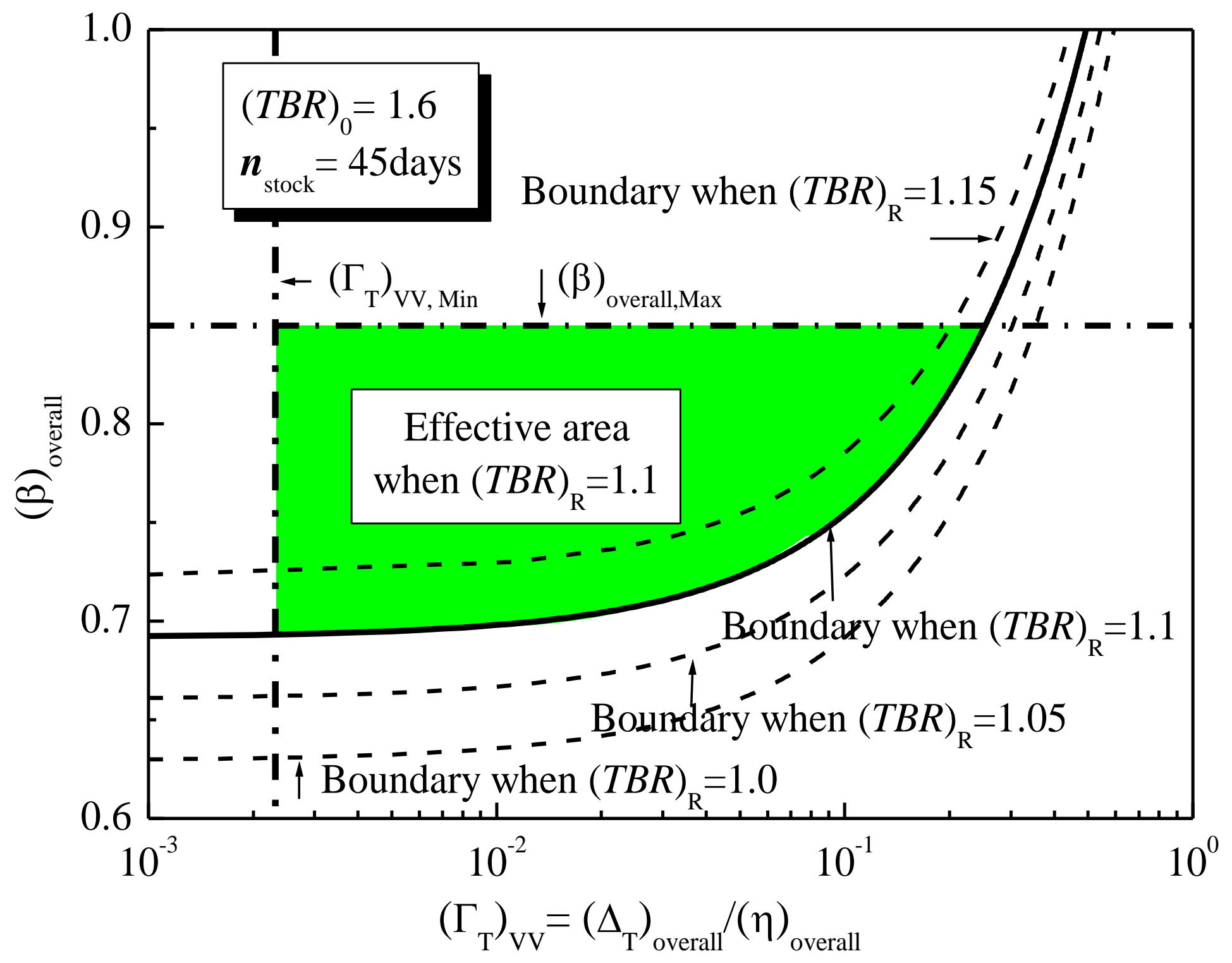

Fig. 6. Effective area to give affirmative value for tritium balancing factor in $\left(\Gamma_{\mathrm{T}}\right)_{\mathrm{VV}^{-}}(\beta)_{\text {overall }}$ chart (parameter: $\left.(T B R)_{\mathrm{R}}\right)$. 